\title{
Investigation of Mechanical State of Reinforced Beams with Cracks by the ZI Method: Algorithm and Calculation Results
}

\author{
Michail SAMOFALOV*, Ipolitas Z̈IDONIS ** \\ *Klaipéda University, Bijūnu 17, LT-91225 Klaipéda, Lithuania, E-mail: michail.samofalov@ku.lt \\ **Klaipéda University, Bijūnu 17, LT-91225 Klaipéda, Lithuania \\ crossref http://dx.doi.org/10.5755/j02.mech.26836
}

\section{Introduction}

During designing of reinforced concrete beams, it is important to know formulas from design codes and also to understand the physical meaning of a phenomenon. The applying the real deformation laws of materials is unusual and irrational for an engineer. In this paper proposed calculation method is a compromise between high accuracy and volume of costs.

Generally, reinforced concrete structures at different deformation stages are considered: elastic, inelastic, when cracks occurred by using a cracked structural member at the destruction moment. On each of the stages it is important to properly determine the values of mechanical state parameters. Both in valid design codes of West Europe (EN 1992, etc.) and in East Europe (Russian SNiP, Ukrainian DBN, etc.) the stress distribution in a cross section is simplified and expressed by a triangle or rectangle shape. Such approximate is acceptable for many civil engineers, but it is non-universal and inaccurate, and sometimes may be incorrect.

Nowadays the finite element method is very popular in a structural analysis. However, it has some deficiencies: an exact model may be complex enough; an approximation level of results depends on skills of a designer; each next problem needs to be re-modelled, etc. In design and expertise companies, in addition to finite element software, to verify the given results, more accurate analytical engineering methods are applied, one of which is presented by this paper, i.e. the ZI method.

Ehsani et al. [1] experimentally investigated 4 reinforced concrete beams, two of which contained $2 \%$ of steel fibres. There were load-strain graphs presented. The authors compared the given results for structural members with different mechanical properties of materials. Slaitas et al. [2] during experiments tested 6 reinforced concrete beams. The flexural strengths were calculated by 7 various methods (one of which was the ZI method). There were bearing capacity reserves and crack depths investigated. A comparison was made. Some experimental investigations of this problem were early presented by Jokūbaitis et al. [3] and others [4]. In Golyshev et al. [5, 6] and Gvozdev's [7] a review of XX century analytical methods and experimental tests in East Europe is presented.

Filatov and Suvorov [8] presented a stepperinteractive algorithm, which considers the stress state of a normal section, by using diagrams $\sigma-\varepsilon$ of real materials. The damaged zone with cracks was also investigated. Modern computer algebra software was applied. The proposed decision is precise in load-history aspects, but it is complicated enough for an engineer.

Raue and Timmler presented [9] a geometrically and physically non-linear model, which is based on the analysis of the potential energy. An example of a column under compression and bending was presented, taking into account the development of cracks. Such general model is difficult for the direct usage by engineers in practice, because of integration and optimization processes.

The presented paper is an extension in the applied direction of monographs [10, 11] about the ZI method, key solutions of which are based on the classic engineering theory of the beam section stress/strain state (Fig. 1).

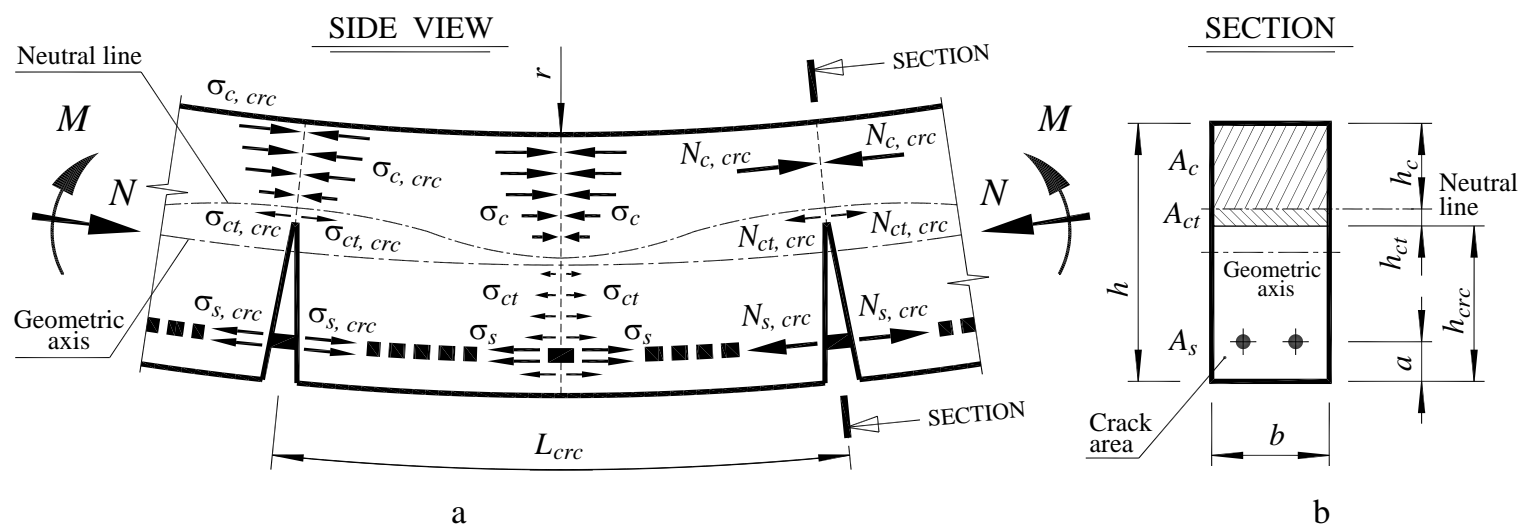

Fig. 1 A scheme of a beam with cracks under compression with bending: a) side view; b) section view

Here, cross sections are acting by a combination of an axial force and the bending moment, real $\sigma-\varepsilon$ diagrams of using materials are directly applied. Such analysis is very actual one for reinforced concrete, because of the non-linear character of stress distribution and cracks.

The ZI method has many advantages: simple in 
the usage, obvious for an engineer, universal, practical, continuous, using real properties of materials, etc. The results, determined by this method, were compared with experimental ones, and with calculations according the design codes EN 1992. A high compliance of the results was observed [12, 13].

On the other hand, the ZI method allows simply calculating with reliability 50,95 or $\sim 100 \%$ [14]. Next possibilities of the usage of the ZI method should be investigated.

The aim of the paper is to analyse the mechanical state of various sections of reinforced concrete beams with cracks. The more general aim is to explain the suitability and convenience of the ZI method, among the usage of other methods. A special attention has been paid to the description of the algorithm and to illustrate the calculation results of examples.

\section{Main concept, assumptions}

When a reinforced beam is loaded, the compressive stress diagram in the cross section changes the shape: at the elastic stage it is close to a triangular one; beyond the point of the strength limit it is becoming more and more like a rectangle one; before destruction the crack area decreases the compressive zone and change the stress distribution. In a general formulation the problem is nonlinear. A practical engineer is interested in a simple result: the load-bearing capacity and the required reinforcement in a cross-section under a load combination of an axial force and bending moment. The question of the cracking history is irrelevant for him. Namely, such kind of the approach is considered in the design codes, in which non-linear diagrams $\sigma-\varepsilon$ are presented (Fig. 2), but any exact method for applying of these general functions is not explained.

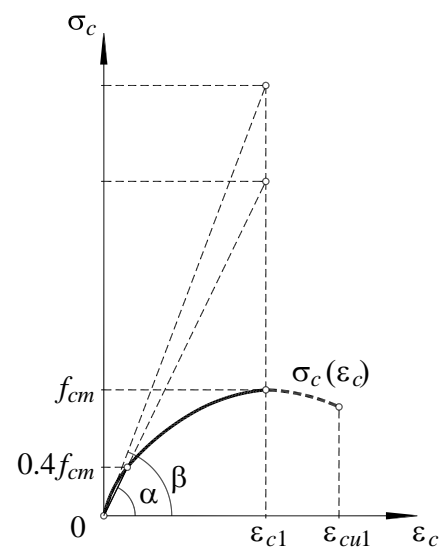

Fig. 2 The compressive concrete stress/strain relation from the design code EN 1992

Since a cross section is subjected only by normal stresses $\sigma$ of an axial force $N$ and bending moment $M$, the one-direction mechanical state is acted in each node of the cross section. Therefore, to use uniaxial test diagrams of materials it is very appropriate. Reinforced concrete is a non-homogeneous material, and additionally the cracks appear, so under loading a complex stress state is formed.

There are some assumptions in our investigation:

- the curve $\sigma-\varepsilon$ (Fig. 2) is described by a polynomial;

- the polynomial of 3rd order is applied for concrete under compression and under tension;
- for reinforcement steel Prandtl's diagram is used;

- Bernoulli's hypothesis of plane sections is valid;

- maximal stresses of the compressive zone can be $f_{c m}$;

- maximal strains of the compressive zone can be $\varepsilon_{c 1}$ for concrete or $\varepsilon_{y}$ in the tensile zone for steel;

- Young's modulus is the same for compressive concrete and for tensile concrete [5].

As we can see (Fig. 1), when the cracks appear, two cross sections become the main ones: at the crack and in the middle between the cracks. Other neighbouring sections are in intermediate states.

Examples in the monograph [10, 11] consider two ways to calculate the cross sections in the middle between cracks of a beam:

I. Prof. A. Rozenblium's method [15], where the plane section hypothesis is applied to the whole cross section, and the strains of tensile concrete is determined by the limit strain, which saves even with increasing load. Bernoulli's hypothesis is not applied for tensile reinforcement steel.

II. The ZI author's method [10, 11], when the plane section hypothesis is applied to compressive concrete and tensile reinforcement, but it is not applied for tensile concrete. It is assumed, that for tensile concrete the limit stress (not limit strain) is used the same one, when even the load values are increasing.

In our opinion, the first method does not take into account the fact, that the tensile concrete is placed between two cracks, so the assumption of homogeneity is not valid for such case and the mechanical conditions are different (unlike the non-cracked reinforced concrete).

By solving the task by the second method, we consider, that the tensile concrete is represented by a tensile reinforcement, which ensures kinematic consistency through the whole cross section and saves the plane of the deformed section. This way is more appropriate to design code EN 1992, and it is a more logical one [10, 11].

In the beam cross section at the crack, Bernoulli's hypothesis applies to both compressive and tensile concrete together with tensile reinforcement.

In the paper, two problems are solved by the ZI method:

1. cross section at the crack (index $\operatorname{crc}$ is used);

2. cross section in the middle between two cracks.

In EN 1992 no recommendations are given to describe the relation $\sigma-\varepsilon$ of tensile concrete.

\section{Stress/strain equation in design code EN 1992}

In the design code EN 1992 the stress/strain relation (Fig. 2) is presented by such function:

$$
\sigma_{c}\left(\varepsilon_{c}\right)=\frac{k \cdot \eta\left(\varepsilon_{c}\right)-\eta^{2}\left(\varepsilon_{c}\right)}{1+(k-2) \cdot \eta\left(\varepsilon_{c}\right)} \cdot f_{c m},
$$

when the strain influence is expressed as:

$$
\eta\left(\varepsilon_{c}\right)=\frac{\varepsilon_{c}}{\varepsilon_{c 1}}
$$

and the constant coefficient is: 


$$
k=\frac{1.05 \cdot E_{c m} \cdot \varepsilon_{c 1}}{f_{c m}}
$$

Parameters $f_{c m}, E_{c m}, \varepsilon_{c 1}$ are chosen from EN 1992.

\section{An alternative stress/strain equation, applying to the cross-sectional distribution of the stresses}

In the ZI method, a below-presented 3rd order polynomial non-dimensional function is used as a correction factor $p<1$ for the Young's law:

$$
p\left(\varepsilon_{c}\right)=1+c_{1} \cdot \eta\left(\varepsilon_{c}\right)+c_{2} \cdot \eta^{2}\left(\varepsilon_{c}\right) .
$$

It is applied for the curved stress/strain relation $\sigma(\varepsilon)$ during the compressive stress interval from 0 to $f_{c m}$ (Fig. 2):

$$
\sigma_{c}\left(\varepsilon_{c}\right)=E_{c} \cdot \varepsilon_{c} \cdot p\left(\varepsilon_{c}\right),
$$

where: $E_{c}=1.05 \cdot E_{c m}$ is tangent modulus (angle $\beta$ on Fig. 2) of elasticity of normal concrete. The coefficients $c_{1}$ and $c_{2}$ in Eq. (4) are expressed by formulas:

$$
c_{1}=3 \cdot \frac{1}{k}-2 \text { and } c_{2}=1-2 \cdot \frac{1}{k} \text {. }
$$

In the cross-sectional $x$-direction of the height $h$, the strain function $\varepsilon_{c}=\varepsilon_{c}(x)$ is variable, because it depends on co-ordinate $x$. Hence, the stresses depend on $x$ also:

$$
\sigma_{c}(x)=E_{c} \cdot \varepsilon_{c}(x) \cdot p(x) .
$$

An internal force and bending moment are integrated through the height of the cross-sectional compressive zone (Fig. 1):

$$
\begin{aligned}
& N_{c}(x)=\int_{0}^{x_{w}} \sigma_{c}(x) \cdot b \cdot \mathrm{d} x, \\
& M_{c}(x)=\int_{0}^{x_{w}} \sigma_{c}(x) \cdot b \cdot x \cdot \mathrm{d} x .
\end{aligned}
$$

Here, the co-ordinate $x_{w}$ describes the top of the cross section. In fact, a distance from 0 to $x_{w}$ is the height $h_{c}$ of the concrete compressive zone. After mathematical operations the internal actions are found:

$$
\begin{aligned}
& N_{c}(x)=\omega_{n c}(x) \cdot \varepsilon_{w} \cdot E_{c} \cdot b \cdot x_{w}, \\
& M_{c}(x)=\omega_{m c}(x) \cdot \varepsilon_{w} \cdot E_{c} \cdot b \cdot x_{w}^{2} .
\end{aligned}
$$

Here, the compressive strain $\varepsilon_{w}$ describes the maximal value at the top of the cross section. Results of integration operations are expressed by following formulas:

$$
\omega_{n c}(x)=\frac{1}{2}+\frac{1}{3} c_{1} \cdot \eta(x)+\frac{1}{4} c_{2} \cdot \eta^{2}(x),
$$

$$
\omega_{m c}(x)=\frac{1}{3}+\frac{1}{4} \cdot c_{1} \cdot \eta(x)+\frac{1}{5} \cdot c_{2} \cdot \eta^{2}(x) .
$$

where: coefficients $c_{1}$ and $c_{2}$ have been at Eq. (6).

\section{Solution algorithm}

In the classic manner, this algorithm is presented by three stages (Fig. 3): input, main stage of an iterative solving, output. For realisation the computer algebra software Maple has been used.

At the prior stage, information about key parameters, assumptions and initial technical data (geometrical characteristics, forces, materials and so on) are stated. For the first step an unknown maximal strain $\varepsilon_{w}$ in the crosssectional compressive zone is preliminary set.

During the iterative stage, above-described by Eqs. $(4-9)$, the integral force $N_{c}$ and moment $M_{c}$ are determined by using algebraic expressions Eq. (10). In the same way $N_{t}$ and $M_{t}$ for the tensile zone are given, actions $N_{s}$ and $M_{s}$ for reinforcement are solved by analytic formulas. Later, the formation of equilibrium equations and formulation of a polynomial for $x_{w}$ are followed. After solving, we should choose a real value and re-calculate $\varepsilon_{w}\left(x_{w}\right)$. Next, a tolerance $\Delta \varepsilon_{w}$ of the strain is checked. In case of a false result, we repeat the calculation. In case of a true one, static equilibrium equations $\Sigma(N)$ and $\Sigma(M)$ are checked. The main accent of the cycle calculations is to determinate a location of the neutral line, where $\sigma=0$.

The last stage is the presentation of results and comparison with the experimental ones.

\section{Calculations examples using the ZI method}

In experiments the used beams $[16,17]$ were selected for calculation by the ZI method. Three groups No. 7, 8 and 9 (Table 1) of reinforced concrete beams were tested to the destruction ( 2 beams in each group).

The elastic modulus of reinforcement was $E_{s}=205 \mathrm{GPa}$, the yield strength was $\sigma_{y}=428 \mathrm{MPa}$, for all tested reinforced concrete beams. The calculations have considered the stage of maintenance of cracked structures. During the testing, the middle part of the beam, subjected only to increasing bending moment and constant axial force was checked (Fig. 4). The destruction moment $26.0 \mathrm{kNm}$ was fixed for the beams of the 7th group, $30.8 \mathrm{kNm}$ - for the 8 th group, $30.0 \mathrm{kNm}$ - for the 9 th group.

Table 1

Initial data from experiments

\begin{tabular}{|c|c|c|c|c|c|c|}
\hline $\begin{array}{c}\text { Group } \\
\text { No. }\end{array}$ & $\begin{array}{c}b, \\
\mathrm{~mm}\end{array}$ & $\begin{array}{c}h, \\
\mathrm{~mm}\end{array}$ & $\begin{array}{c}a, \\
\mathrm{~mm}\end{array}$ & $\begin{array}{c}A_{s}, \\
\mathrm{~cm}^{2}\end{array}$ & $\begin{array}{c}f_{c m}, \\
\mathrm{MPa}\end{array}$ & $\begin{array}{c}N_{E m}, \\
\mathrm{kNm}\end{array}$ \\
\hline 7 & 112 & 244 & 37.5 & 3.2 & 25.6 & +7.9 \\
\hline 8 & 110 & 242 & 32.0 & 3.3 & 34.8 & +0.7 \\
\hline 9 & 111 & 239 & 32.0 & 3.3 & 42.0 & -2.9 \\
\hline
\end{tabular}

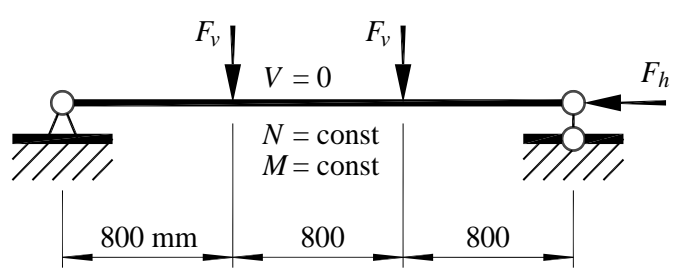

Fig. 4 The testing scheme of beams 


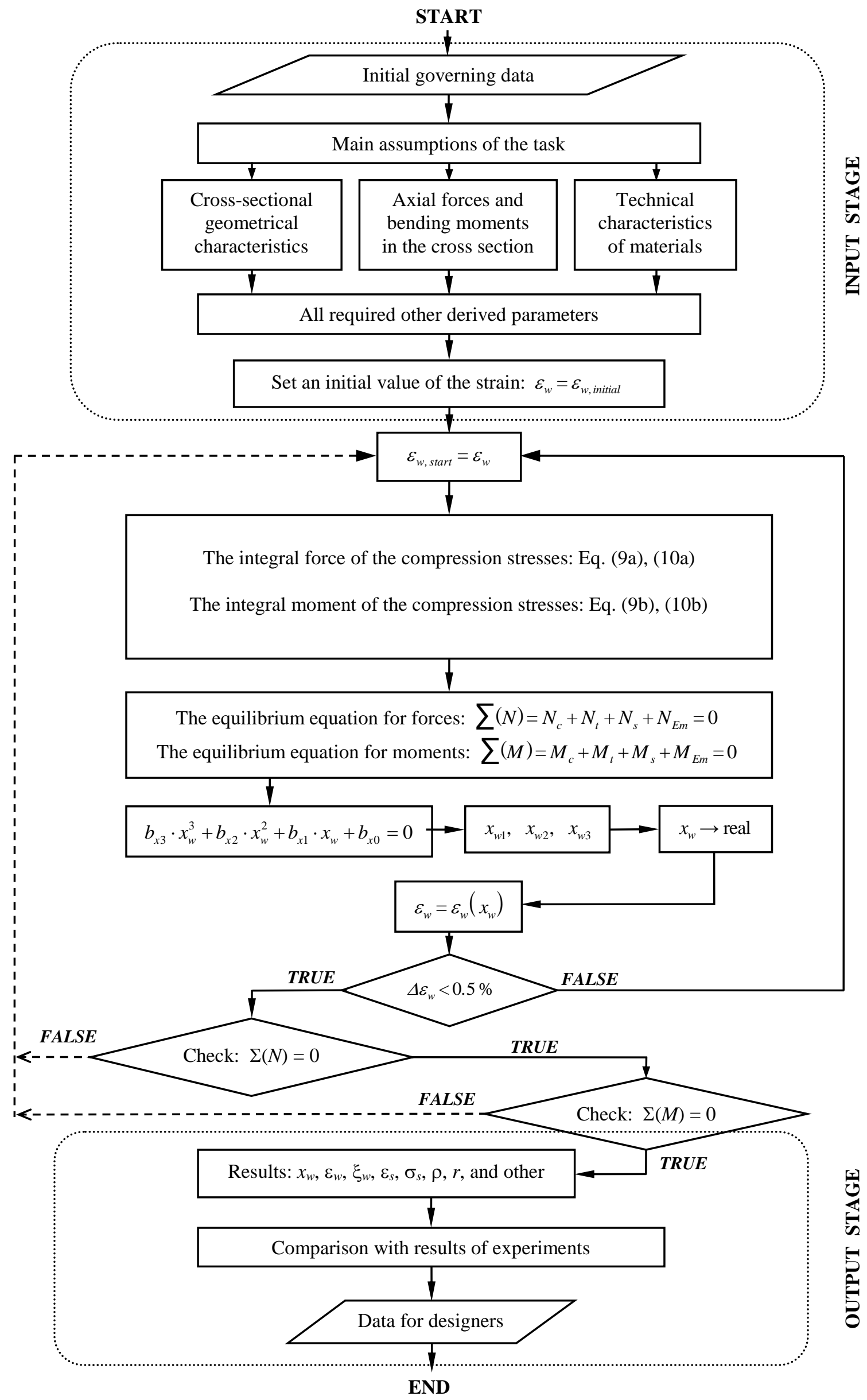

Fig. 3 The algorithm of the mechanical state analysis of a reinforced beam by the ZI method 
In the cross section at the crack, the reinforced concrete beam becomes a steel-concrete complex structure, in which steel bars have no direct contact with the concrete and work mechanically separately (Fig. 1). Immediately after the crack formation, the redistribution of stresses occurs. Due to the cracks, the kinematic boundary conditions of the Theory of the Deformable Body are changed: the tensile concrete at the cracks becomes loose, and the tensile concrete in the middle between cracks still remains tensed together with the reinforcement steel. When the concrete cracks, the steel itself reacts in its own manner the strains increase at the free space in the crack.

In the cross section between the cracks, the forces of the direct contact between reinforcement and concrete act. The distance between the cracks (Fig. 1) is usually expressed by 2 anchoring lengths of the reinforcement, so the strains are accumulated from crack to crack. When the cracks open, the cracking process is stabilized. The states of all other adjacent sections are intermediate ones.

To explain the results according to the calculation by the ZI method of the 7th group of the experimental beams, when the moment $14.0 \mathrm{kNm}$ is acted, equilibrium of cross-sectional forces, strain and stress diagrams are presented for the cross section at the crack (Fig. 5) and for the cross section between cracks (Fig. 6).

The relation of parameters, depending of changing of the bending moment, has been investigated, starting from $\sim 1 / 5$ (when cracks occurred) of the limit moment $M_{\text {test }}$ to the destruction of the beam.

In the formed Soviet Union in 1965 according to prof. A. Gvozdev [18], there is no method to link cracks in a reinforced concrete beam and tensile concrete layer with beam deflections. Such kind of problems was solved by prof. A. Rozenblium (Lithuania), and the ZI method extends this calculation.

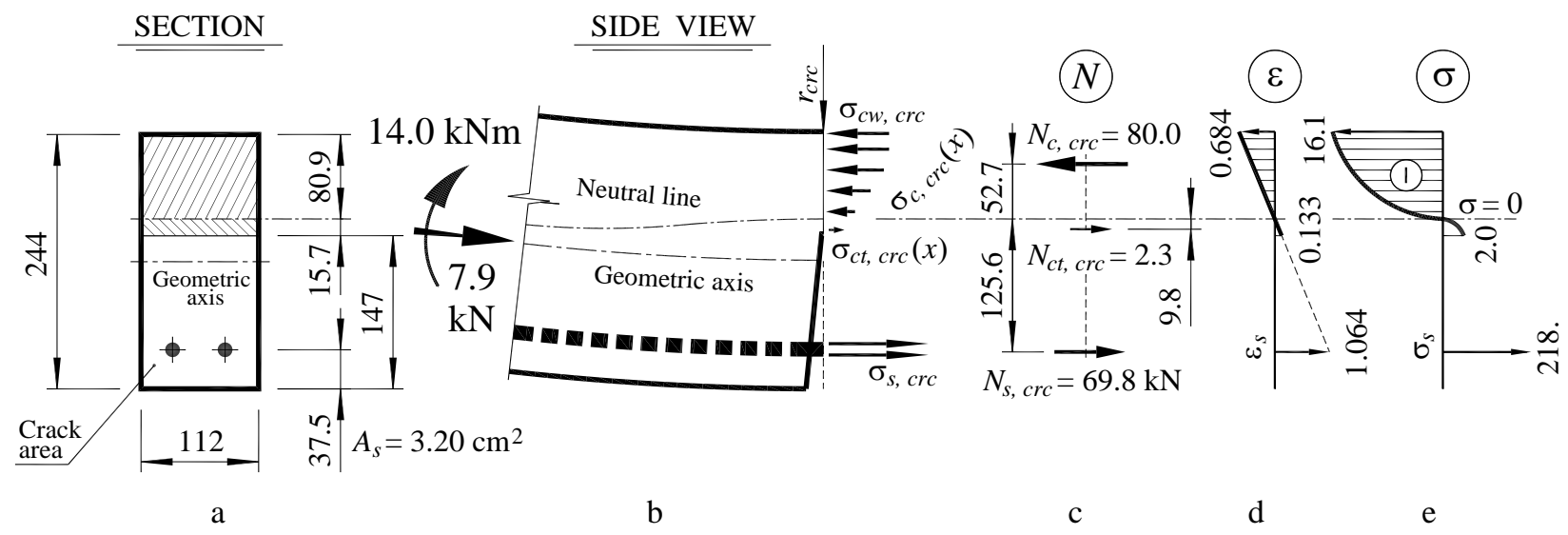

Fig. 5 The calculation scheme and results of the beam cross section at the crack: a) section view; b) side view; c) crosssectional forces; d) diagram of strains; e) diagram of stresses

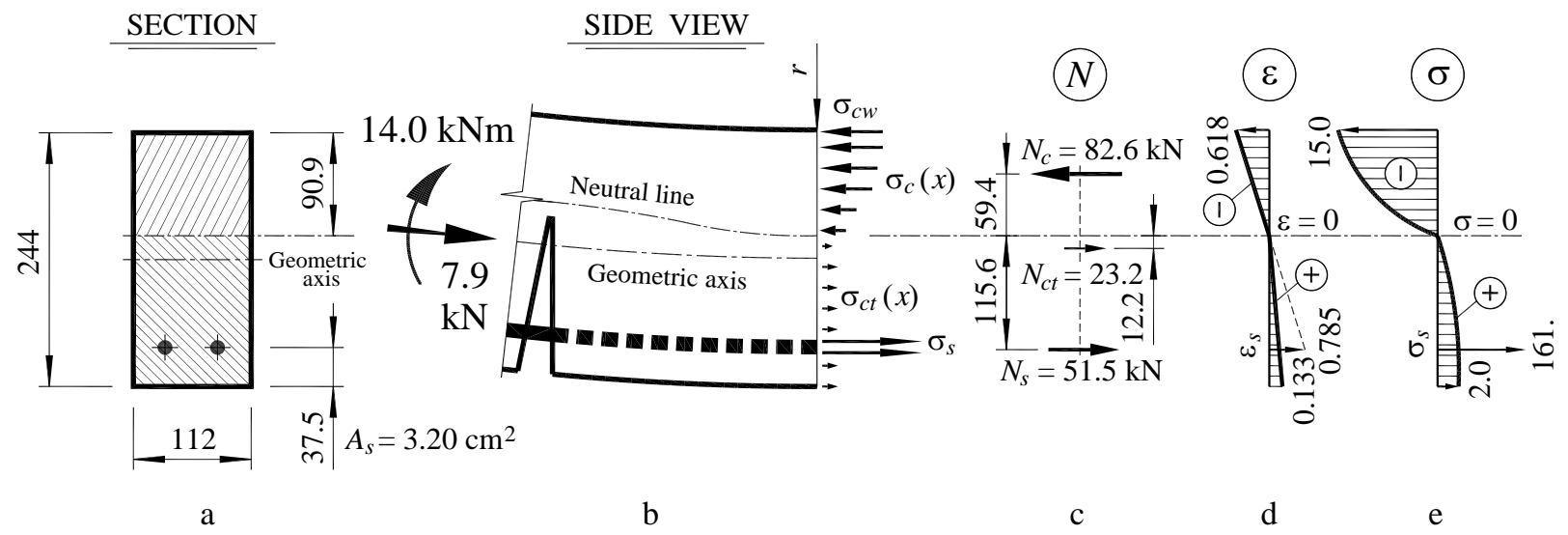

Fig. 6 The calculation scheme and results of the beam cross section in the middle between cracks: a) section view; b) side view; c) cross-sectional forces; d) diagram of strains; e) diagram of stresses

At the first, for above-described beam groups No. 7, 8 and 9 the variation of the relative cross-sectional height $h_{c} / d$ of the compressive zone, the relative height $h_{c t} / d$ of the tensile zone and the relative height $h_{c r c} / d$ of the crack deep, depending on the relative bending moment $M_{E m} / M_{\text {test }}$, have been considered (Fig. 7). To compare the values, the "working" cross-sectional height $d=h-a$ of the reinforced concrete beam (Fig. 1) is chosen, which is an ordinary and acceptable for a civil engineer.

On the graph (Fig. 7), the continuous lines show the results of the 7 th beam group, the dashed lines are for 8th group, and the dotted ones are for 9th group. The same marking has been used for lines on Figs. 8, 9 and 12.

The graph (Fig. 7) points, that the $h_{c} / d$ value is the highest $0.422-0.469$ at the prime relative bending moment $0.15-0.20$. As the moment increases to 0.5 , the ratio $h_{c} / d$ decreases to $0.348-0.392$, and near the relative moment 1.0 it slowly increases again to $0.362-0.413$. When the crack occurs at the moment $0.15-0.20$, the tensile layer is the thickest of $0.302-0.318$, and the crack is the smallest, i.e. $0.410-0.438$. Near the middle of the graph, when the moment is about 0.6 , the value $h_{c t} / d$ decreases rapidly to 
$0.065-0.078$, and the crack $h_{c r d} / d$ increases to $0.715-0.727$. At the moment 1.0, the ratio $h_{c t} / d$ is only $0.036-0.046$, and the crack increases to $0.729-0.748$. The curvature of all lines shows, that as the bending moment grows, the distribution of forces is non-linearly changed. The most important influence on the process has the decrease of the thickness of the tensile concrete layer.

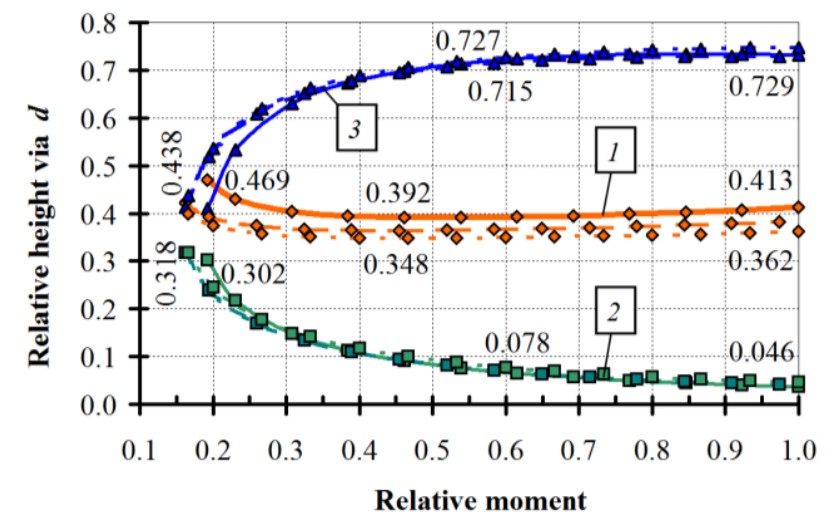

Fig. 7 The variation of relative cross-sectional height of zones, depending on the relative bending moment: 1 - compressive layer; 2 - tensile layer; 3 - crack deep

Second, the relation of relative strains $\varepsilon_{c} / \varepsilon_{c 1}$ at the top on the cross section at the crack of beams for the 7,8 and 9th groups, depending of the relative moment $M_{E m} / M_{\text {test }}$, has been investigated (Fig. 8). The value of concrete strains $\varepsilon_{c} / \varepsilon_{c 1}$ at the relative bending moment 0.15 0.20 is $10-14 \%$ and during the loading process increases evenly with lowly curvature to 63,71 ir $79 \%$, depending of the strength of concrete (for stronger concrete, the value of $\varepsilon_{c} / \varepsilon_{c 1}$ is lower). The relative strains $\varepsilon_{s} / \varepsilon_{y}$ of the reinforcement increase almost linearly from $11-16$ to $103-119 \%$. As we can see, the relative values of concrete are lower in comparison with the relative values of reinforcement, so the limit state of the reinforcement steel is reached earlier than in concrete, for such kind of beams.

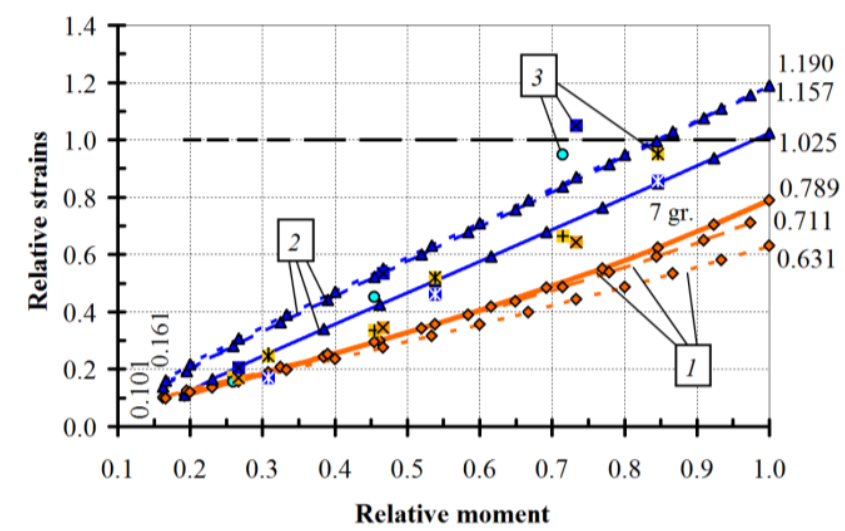

Fig. 8 The variation of relative strains, depending on the relative bending moment 1 - the top point of concrete; 2 - reinforcement; 3 - experimental data

Comparison of concrete relative strains $\varepsilon_{c} / \varepsilon_{c 1} \mathrm{ob}-$ tained from calculations with experimentally given $\varepsilon_{c, \text { test }} / \varepsilon_{c 1}$ shows (Fig. 8), that the differences are the follow (Table 2). Comparison of the relative reinforcement strains $\varepsilon_{s} / \varepsilon_{y}$ with experimental ones $\varepsilon_{s, \text { test }} / \varepsilon_{y}$ shows the following differences (Table 3 ). Thus, in the cross-sectional calcula- tion, the distribution of strains between concrete and reinforcement steel deviates by 16-25\%. Probably, a crosssectional distortion appears, because strains deviate from the plane section, although this hypothesis is considered as an underlying one in the ZI method. Of course, there may be other reasons, such as scale factor, etc.

Table 2

Differences of relative strains of concrete

\begin{tabular}{|c|c|c|c|c|c|c|}
\hline $\begin{array}{c}\text { Group } \\
\text { No. }\end{array}$ & $\frac{M}{M_{\text {test }}}$ & $\begin{array}{c}\Delta \varepsilon_{c}, \\
\%\end{array}$ & $\frac{M}{M_{\text {test }}}$ & $\begin{array}{c}\Delta \varepsilon_{c}, \\
\%\end{array}$ & $\frac{M}{M_{\text {test }}}$ & $\begin{array}{c}\Delta \varepsilon_{c}, \\
\%\end{array}$ \\
\hline 7 & 0.308 & +30 & 0.538 & +45 & 0.846 & +52 \\
\hline 8 & 0.260 & +3 & 0.455 & +13 & 0.714 & +36 \\
\hline 9 & 0.267 & +7 & 0.467 & +25 & 0.733 & +45 \\
\hline
\end{tabular}

Table 3

Differences of relative strains of reinforcement

\begin{tabular}{|c|c|c|c|c|c|c|}
\hline $\begin{array}{c}\text { Group } \\
\text { No. }\end{array}$ & $\frac{M}{M_{\text {test }}}$ & $\begin{array}{c}\Delta \mathcal{E}_{s}, \\
\%\end{array}$ & $\frac{M}{M_{\text {test }}}$ & $\begin{array}{c}\Delta \mathcal{E}_{s}, \\
\%\end{array}$ & $\frac{M}{M_{\text {test }}}$ & $\begin{array}{c}\Delta \varepsilon_{s}, \\
\%\end{array}$ \\
\hline 7 & 0.308 & -33 & 0.538 & -10 & 0.846 & +1 \\
\hline 8 & 0.260 & -44 & 0.455 & -13 & 0.714 & +14 \\
\hline 9 & 0.267 & -33 & 0.467 & -3 & 0.733 & +21 \\
\hline
\end{tabular}

Third, variation of the relative stresses $\sigma_{c} / f_{c m}$ at the top cross-sectional layer and the relative stresses in the reinforcement steel $\sigma_{s} / \sigma_{y}$, depending of changing of the relative bending moment $M_{E m} / M_{\text {test }}$ have been investigated (Fig. 9). The stress analysis shows, that the value of relative concrete stresses $\sigma_{c} / f_{c m}$ at the relative bending moment $0.15-0.20$ is $18-23 \%$ and all the loading time increases evenly to 85,92 ir $97 \%$ with insignificant deflection, depending of the concrete strength (for stronger concrete, the value $\sigma_{c} / f_{c m}$ is lower). The relative stresses $\sigma_{s} / \sigma_{y}$ of the reinforcement steel increase by the almost linear dependence from $11-16$ to $103-119 \%$.

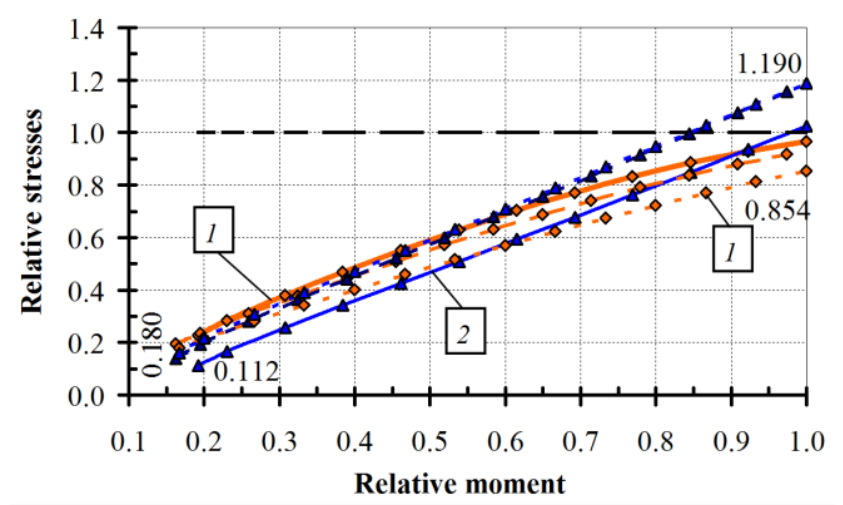

Fig. 9 The variation of relative stresses, depending on the relative bending moment: 1 - the top point of concrete; 2 - reinforcement

Similarly, like the cross section at the crack, the cross section at the middle between two cracks on each of modelled beams (Table 1) has been calculated. For example, when the beams of the 7 th group have been acted by the bending moment from 5.0 to $26.0 \mathrm{kNm}$, the change of heights for compressive and tensile cross-sectional zones as well as values of strains and stresses have been analysed. Considering of the distribution (Fig. 10) of the relative stresses $\sigma(x) / f_{c m}$ trough the relative cross-sectional height $x / h$, we see, that as the bending moment increases, 
the diagram line bends and deviates from the forward direction, i.e. non-linear properties have been more and more developed in concrete. At the same time, with the growing bending moment, we see a change of the position of the cross-sectional neutral line.

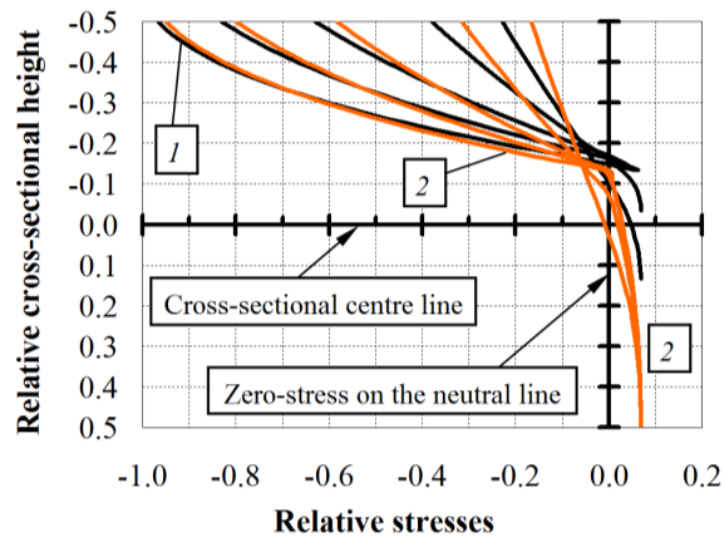

Fig. 10 The distribution of relative stresses in the direction of the cross-sectional height, when the bending moment 5.0, 8.0, 14.0, 20.0 and $26.0 \mathrm{kNm}$ : 1 - black lines mark the section with cracks, 2 - gray lines denote the whole section

On the stress graph (Fig. 10), the stresses of the whole cross section "delay" in comparison with the stresses in the cracked cross section. At the same time, it can be seen, that the compressive zone of the whole cross section is always higher than the compressive zone in the cross section with the crack.

\section{The plane section hypothesis in the ZI method}

The deviation from the plane section of the real strains in the tensile reinforcement steel in a cross section of a bending reinforced concrete beam is expressed by using the correction factor $k_{s}$. As it was discussed early, in the cross section at the crack, the assumption of the plane section has been applied to all strains: $\varepsilon_{c}, \varepsilon_{c t}$ and $\varepsilon_{s}$. In the cross section between the cracks this assumption has not been used for strains $\varepsilon_{c t}$ of the tensile concrete. That the tensile stresses $\sigma_{c t}(x)$ are close to the limit tensile strength $\sigma_{c t u}$ of the concrete, is evidenced by the appearance of new cracks. It is assumed, that strains in the tensile concrete are geometrically described by another plane section, which does not coincide with the plane section of the whole cross section.

The main role in describing of beam crosssectional strains is played by the concrete compressive zone, because there the strains are completely corresponding to the plane section hypothesis. In the cross-sectional tensile zone, the assumption of material homogeneity is not valid near cracks. Stress and strain fields are also deflected under local laws, taking into account the adhesion contact between concrete and reinforcement steel. Therefore, in the cross section with the crack, a strain lag from the plane section is evaluated by the coefficient $k_{s, c r c}<1$, and in the cross section at the middle between the cracks, we increase the coefficient $k_{s, \text { mid }}>1$ accordingly. From the point of view of engineering accuracy, it is sufficient to use the linear relation:

$$
k_{s, \text { crc }}+k_{s, \text { mid }}=2 \text {. }
$$

Experimental results show [19], that values $k_{s, \text { crc }}<0.6$ and respectively $k_{s, \text { mid }}>1.4$ can occur only during the slip of the reinforcement, which also can appear.

Thus, the change of the beam mechanical state parameters, depending on the coefficient $k_{s}$, has been investigated. Values of this coefficient for the cross section at the crack from 0.5 to 1.0 and for cross section at the middle between cracks from 1.0 to 1.5 have been chosen. It has been calculated for moments $8.0 \mathrm{kNm}$ (continuous lines), $14.0 \mathrm{kNm}$ (dashed lines) and $22.0 \mathrm{kNm}$ (dotted lines). The graph (Fig. 11) shows the results of the 7 th beam group.

The calculation results of the cross section at the crack ( $k_{s}$ from 0.5 to 1.0 ) show, that the relative height $h_{c} / d$ of the compressive concrete layer changes from 31-32 to $39-40 \%$, the relative height $h_{c t} / d$ of the tensile concrete zone increases from 3-9 to 5-15\%, the crack relative depth decreases from $78-83$ to $63-74 \%$. So, the height of the compressive concrete zone almost does not depend on the value of the bending moment. The height of the tensile concrete zone and the corresponding depth of the crack depend on the acting moment and therefore change.

The results of the calculation of the cross section at the middle between cracks ( $k_{s}$ from 1.0 to 1.5 ) show, that $h_{c} / d$ increases from $43-50$ to $49-55 \%$, the values $h_{c t} / d$ decreased from $68-75$ to $63-70 \%$. Both $h_{c} / d$ and $h_{c t} / d$ depends on the values of the bending moment as they change. All graph lines are closed straight lines. A separate paper is needed to describe the effect of the coefficient $k_{s}$.

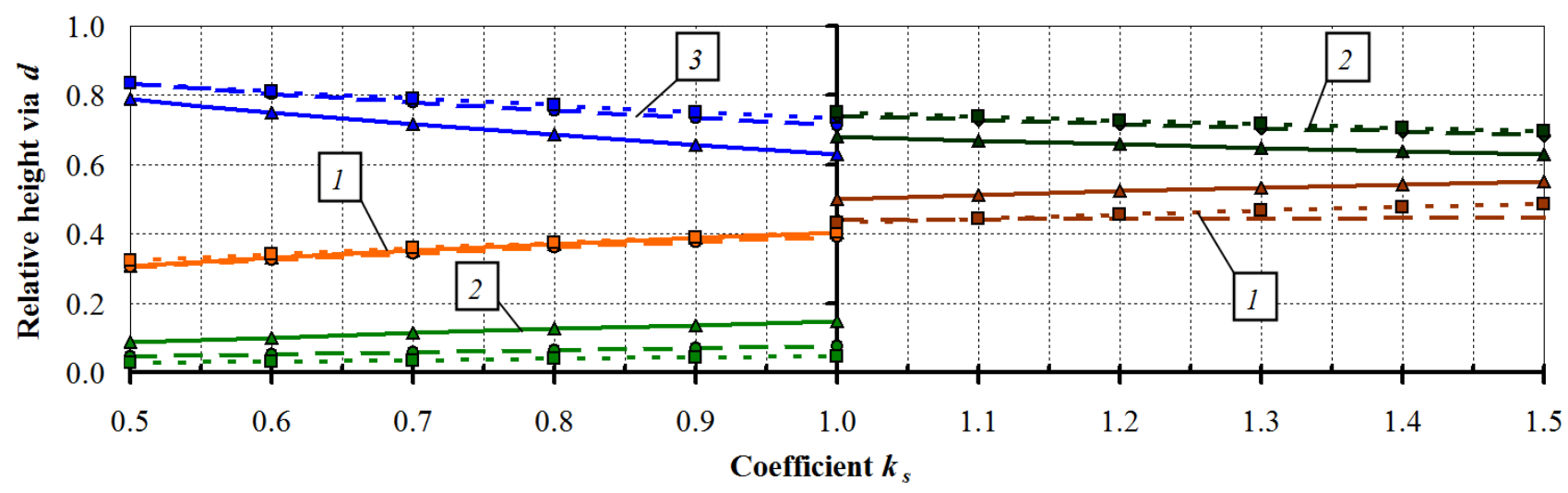

Fig. 11 The variation of the relative cross-sectional height, depending on the coefficient $k_{s}$ ( 7 th beam group): $1-$ height of the compressive layer; 2 - height of the tensile layer; 3 - the crack deep 
The beam cross section at the crack (Fig. 5) and the cross section at the middle between two cracks (Fig. 6) have been curved different, even in our case of pure bending without shear (Fig. 4). To determine the stiffness of a beam, the principle of the average of curvatures $\left(\chi+\chi_{\text {crc }}\right) / 2$ has been applied, which is sufficient from the point of view of technical accuracy. The dependence of the averaged $\left(\sigma_{c}+\sigma_{c, c r c}\right) / 2 f_{c m}$ relative stresses on the top of the cross section for the 7,8 and 9th beam groups via relative curvature $\chi_{\text {mid }} / \chi_{\max }$ has been investigated. Here, $\chi_{\max }$ has been chosen, when the maximum moment $M_{\text {test }}$ has been .

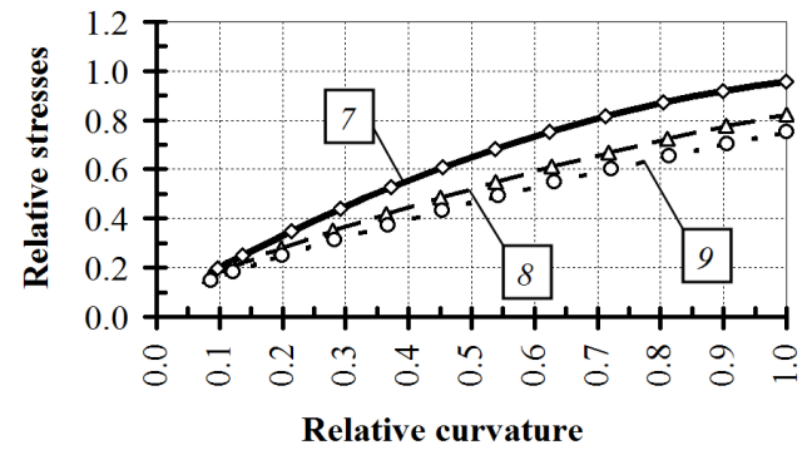

Fig. 12 The variation of relative stresses via the relative curvature (the marks show the numbers of beam groups)

The results indicate (Fig. 12), that the values of the relative stresses on the top of cross-sectional compressive concrete for all groups of beams, when the primary relative bending moment is acting, are $15-20 \%$ and locate near each other. As the moment is increasing to the maximal value, the curves are moving away from each other and at the end the values are 96,82 and $75 \%$, respectively. The line of the 7 th beam group is more distorted than the others. It indicates, that the concrete stresses approach the strength limit $f_{c m}$ faster, the curves are not coincidentally close to diagram $\sigma-\varepsilon$ (Fig. 2).

\section{Conclusions and perspectives}

Based on the presented investigation of the mechanical state of the reinforced concrete beams the following conclusions have been made:

1. The ZI method can be developed to solve various problems for different cross sections. This method is a convenient practical tool for investigation of the mechanical state of beams.

2 . The relations of the height $h_{c}$ of the compressive zone, the height $h_{c t}$ of the tensile zone and the depth of the opened crack $h_{c r c}$ of the cross section at the crack of three groups of reinforced concrete beams under bending and axial force have been presented.

3. The relations of the maximal compressive strains on the top of the beam cross section and strains in the reinforcement steel, depending of the bending moment, have been investigated. The calculation results have been compared with laboratory tests of such beams.

4. The relations of the maximal compressive stresses on the top of the beam cross section and stresses in the reinforcement steel, depending of the bending moment, have been described. The calculation results of the cross section at the crack (cross-sectional zones, strains, stresses, curvatures, etc.) have been compared with the results, giv- en for the cross section between cracks.

5. The possibility to consider the problem of strain deviation from the plane section for the reinforcement steel has been illustrated by the correction factor $k_{s}$.

6. The considered ZI method is especially effective when it is necessary to exactly determine the strain state parameters as curvatures, deflections, etc., because the accuracy of this method is higher than the engineering methods currently used in design codes, mainly based on experimental tests.

7. The ZI method lets make a more accurate analysis of the mechanical state of a cross section, when diagrams of materials are non-linear. In structural designing, it is useful to use the ZI method as an alternative to the currently used method in design codes, and it would be especially convenient for an engineer to automate calculations, of course.

\section{References}

1. Ehsani, R.; Sharbatdar, M. K.; Kheyroddin, A. 2019. Ductility and moment redistribution capacity of two-span RC beams, Magazine of Civil Engineering 90(6): 104-118.

https://engstroy.spbstu.ru/userfiles/files/2019/6(90)/10. pdf

2. Slaitas, J.; Hlavac, Z.; Šneideris, A. 2017. Flexural reinforced concrete elements normal section bearing capacity evaluation in fracture stage, Engineering Structures and Technologies 9(2): 70-78.

https://doi.org/10.3846/2029882X.2017.1322919.

3. Jokūbaitis, V.; Juknevičius, L.; Šalna, R. 2013. Conditions for failure of normal section in flexural reinforced concrete beams of rectangular cross-section, The 11th Int Conf Modern Building Materials Struct and Techniques, Procedia Engineering 57(2013): 466-472. https://doi.org/10.1016/j.proeng.2013.04.060.

4. Lisauskas, T.; Augonis, M.; Zingaila, T.; Arruda, M. R. T. 2020. Stiffness and strength analysis of flexural RC beams strengthened with CFRP sheets considering the influence of pre-cracking, Mechanika 26(4): 277-284. http://dx.doi.org/10.5755/j01.mech.26.4.25064.

5. Golyshev, A. B.; Krivosheev, P. I.; Bambura, A. N. 2009. Theory of reinforced concrete on experimental basis. Kiev: Gamma-Print. 397 p. (in Russian).

6. Bambura, A. N. et al. 1987. Methodical recommendations for accurate calculation of reinforced concrete members, taking into account the complete concrete compression diagram. Kiev: NIISK. 25 p. (in Russian).

7. Gvozdev, A. A. 1949. Calculation of structural bearing capacity by the method of limit equilibrium. Moscow: Stroyizdat, 280 p. (in Russian).

8. Filatov, V. B.; Suvorov, A. A. 2016. Research of the stress condition of the normal section of reinforced concrete elements using nonlinear deformation model, Procedia Engineering 153: 144-150.

Available online at www.sciencedirect.com.

9. Raue, E.; Timmler, H. G. 2007. Non-linear analysis of deformations of reinforced concrete elements by non-linear mathematical optimization, The 9th Int Conf Modern Build Mat Struct and Techn vol. 3: 1049-1053. https://publons.com/journal/164477/9th-internationalconference-modern-building-mater/. 
10. Židonis, I. 2018. The ZI Method and its Application for Calculating of Stress-Strain Parameters of Structural Members. Monograph. Klaipedda University, Sciendo. $564 \mathrm{p}$.

https://www.degruyter.com/view/product/512877.

11. Židonis, I. 2018. The ZI Method and Its Use for the Calculation of Stress-strain Parameters of Structural Members. Monograph. Klaipeda University. 557 p. (in Lithuanian).

https://www.ku.lt/leidykla/ tu-rinys/leidiniai/laisvaiprieinami-leidiniai/zi-metodas-ir-jo-panaudojimaskonstrukciniu-elementu-itempiu-de-formaciju-buvioparametrams-apskaiciuoti/.

12. Židonis, I. 2014. The third equilibrium equation for forces of flexural member cross-section, Mechanika 20(2): 127-134.

https://doi.org/10.5755/j01.mech.20.2.6942.

13. Židonis, I. 2009. Method for a direct calculation of stress-strain state parameters at normal right-angled sections of structural members given curvilinear stress diagrams, Mechanika 3(77): 27-33. https://mechanika.ktu.lt/index.php/Mech/article/view/1 5236.

14. Židonis, I. 2019. Curvilinear stress-strain relationship for concrete of EN-2 regulation in the ZI method and the calculation of beam strength, Mechanika 25(5): 341-349.

https://doi.org/10.5755/j01.mech.25.5.24453.

15. Rozenblumas, A.; Jokūbaitis, V. 1965. On the question of determining the zone of tensile concrete over cracks in bending reinforced concrete elements, XV Conf., Vilnius (in Lithuanian).

16. Židonis, I. J. 1973. Investigation of stresses and strains of members with different tensile zone under static action of short-time loads, Reinforced Structures 5: 5565. (in Russian).

17. Židonis, I. J. 1972. About the work of reinforced concrete members with different tensile zone under shorttime loads. PhD Thesis. Kaunas. 204 p. (in Russian).

18. Gvozdev, A. A. 1964. Development of the theory of reinforced concrete in the USSR, Concrete and Reinforced Concrete 8. (in Russian).

19. Gusakov, V. N. 1967. Calculation of reinforced structures of heavy silicate concrete. Moscow. (in Russian).
M. Samofalov, I. Židonis

\section{INVESTIGATION OF MECHANICAL STATE OF REINFORCED BEAMS WITH CRACKS BY THE ZI METHOD: ALGORITHM AND CALCULATION RESULTS}

\section{S u m m a r y}

The mechanical state of reinforcement concrete beams with cracks, which are acted by axial force and bending moment, is investigated. The considered ZI method is a compromise between high accuracy and volume of costs, when real curve diagrams are applied to describe the properties of materials and solution is rationally simplified by engineering assumptions. The paper presents the main formulas and algorithm for solving of engineering problems by using the ZI method. Three groups of beams have been calculated to represent the results. Two cross sections of cracked reinforced concrete beams have been analysed: at the crack and in the middle between cracks. Depending on increasing of the bending moment, the change of the location of the neutral line has been determined, diagrams of strains and stresses have been made. The possibility to take into account the deviations of the reinforcement strains from the plane section has been illustrated. The values of the bending curvatures of the beams have been also determined. The calculation results have been compared with the results of laboratory experiments, conclusions have been presented.

Keywords: ZI method, stress/strain state, reinforced structural members, non-linear properties of materials.

Received June 24, 2020

Accepted April 07, 2021

This article is an Open Access article distributed under the terms and conditions of the Creative Commons Attribution 4.0 (CC BY 4.0) License (http://creativecommons.org/licenses/by/4.0/). 